\title{
Pengaruh Duduk 5 Menit Dibanding dengan Langsung Dibaringkan pada Pasien yang Dilakukan Anestesi Spinal dengan Bupivakain Hiperbarik 0,5\% 10 mg terhadap Perubahan Tekanan Arteri Rata-rata dan Blokade Sensorik
}

\author{
Raditya Fauzan, ${ }^{1}$ Doddy Tavianto, ${ }^{2}$ Ruli Herman Sitanggang ${ }^{2}$ \\ ${ }^{1}$ SMF Anestesi Rumah Sakit Awalbros Panam, ${ }^{2}$ Departemen Anestesiologi dan Terapi Intensif \\ Fakultas Kedokteran Universitas Padjadjaran/Rumah sakit Dr. Hasan Sadikin Bandung
}

\begin{abstract}
Abstrak
Anestesi spinal sering kali mengakibatkan hipotensi karena blokade simpatis yang tinggi. Penelitian ini bertujuan melihat pengaruh duduk 5 menit dibanding dengan langsung dibaringkan setelah pemberian anestesi spinal dengan bupivakain 0,5\% hiperbarik $10 \mathrm{mg}$ terhadap tekanan arteri rata-rata dan ketinggian blokade sensorik. Penelitian dilakukan dengan metode acak terkontrol tersamar tunggal pada 36 orang pasien dengan status fisik American Society of Anesthesiologist (ASA) I-II yang menjalani operasi perut bagian bawah dan ekstermitas bawah di Rumah Sakit Umum Dr. Hasan Sadikin Bandung pada bulan Maret-Mei 2015. Analisis statistik tekanan arteri rata-rata menggunakan Uji Mann-Whitney dan ketinggian blokade sensorik dengan Uji Kolmogorov Smirnov. Penurunan tekanan arteri rata-rata kelompok 1 (duduk selama 5 menit) lebih sedikit dibanding dengan kelompok 2 (langsung dibaringkan) dengan perbedaan yang bermakna $(p<0,05)$. Ketinggian blokade sensorik rata-rata kelompok 1 terbanyak pada T10 (14 dari 18) dan kelompok 2 pada T6 (8 dari 18). Simpulan, posisi duduk selama 5 menit setelah anestesi spinal dengan bupivakain 0,5\% hiperbarik $10 \mathrm{mg}$ menyebabkan penurunan tekanan arteri rata-rata lebih kecil dan ketinggian blokade sensorik lebih rendah dibanding dengan posisi langsung dibaringkan.
\end{abstract}

Kata kunci: Anestesi spinal, bupivakain 0,5\% hiperbarik, blokade sensorik, posisi badan, tekanan arteri rata-rata

\section{Effects of 5-Minute Sitting Compared to Immediately Lying Down After $10 \mathrm{mg}$ of $0.5 \%$ Hiperbaric Bupivacaine Administration on Mean Arterial Pressure and Level of Sensory Blockade in Patients Receiving Spinal Anesthesia}

\begin{abstract}
Spinal anesthesia frequently results in hypotension due to high sympathetic blockade. The aim of this study was to examine effect of sitting for 5 minutes compared to immediately lying down after $10 \mathrm{mg}$ of $0.5 \%$ hiperbaric bupivacaine administration with regards to the mean arterial pressure and level sensory blockade in patients who underwentd spinal anesthesia. This was a single blind randomized controlled trial in 36 patients with American Society of Anesthesiologists (ASA) I-II undergoing lower abdominal and lower extremities surgery under spinal anesthesia in Dr. Hasan Sadikin General Hospital Bandung during the period of March to May 2015. Data were statistically analyzed using Mann Whitney test for mean arterial pressure and Kolmogorov Smirnov test for level sensory blockade. The results showed a decrease of mean arterial pressure in group 1 (sitting 5 minutes) which was lower than group 2 (immediately lying down) with significant difference $(\mathrm{p}<0.05)$. Level of sensory blockade in group 1 at $\mathrm{T} 10$ (14 from 18) was higher than in group 2 at $\mathrm{T} 6$ ( 8 from 18, $\mathrm{p}=0.001$ ). It is concluded in this study that sitting for 5 minutes after spinal anesthesia using $10 \mathrm{mg} 0.5 \%$. bupivacaine hiperbaric decreases the intraoperative sensory of blockade height and mean arterial pressure.
\end{abstract}

Key words: Bupivacaine, body potition, mean arterial preassure, sensory blockade, spinal anesthesia

Korespondensi: Raditya Fauzan, dr., SpAn, SMF Anestesi Rumah Sakit Awalbros Panam, Jl. H. R Subrantas Panam No. 88 Kota Pekan Baru-Riau, Mobile 0811205641,Email raditfauzan@gmail.com 


\section{Pendahuluan}

Beberapa hasil penelitian membuktikan bahwa blokade neuroaksial mengurangi insidensi trombosis vena sehingga menurunkan angka morbiditas serta mortalitas. Waktu pemulihan fungsi gastrointestinal setelah pembedahan akan lebih cepat dibanding dengan anestesia umum dan efek simpatektomi menyebabkan vasodilatasi yang akan meningkatkan aliran darah sehingga memperbaiki hiperkoagulopati dan menurunkan respons stres neuroendokrin akibat pembedahan.

Pada penyakit jantung koroner, respons stres yang menurun akan mengurangi kejadian iskemia jantung sehingga dapat menurunkan morbiditas serta mortalitas. Selain itu, akan mengurangi kebutuhan opiat sehingga angka kejadian hipoventilasi dan aspirasi pneumonia menurun. ${ }^{1}$

Beberapa faktor utama yang memengaruhi penyebaran obat anestesia lokal antara lain karakteristik obat anestesia lokal (barisitas, dosis, volume, konsentrasi, serta zat aditif), teknik (posisi tubuh, tempat penyuntikan, barbotase,tipe jarum), dan karakteristikpasien (usia, tinggi badan, berat badan, tekanan intraabdomen, kehamilan, serta anatomi tulang belakang). Faktor yang paling menentukan adalah barisitas dan posisi tubuh. ${ }^{1,2}$

Hipotensi sering terjadi pada pasien yang dilakukan anestesia spinal disebabkan blokade simpatik yang tinggi sehingga mengakibatkan perubahan fluktuatif pada tekanan darah. Beberapa upaya untuk mengatasi penurunan tekanan darah antara lain kompresi tungkai bawah, pemberian cairan, dan vasopresor telah terbukti mengatasi hipotensi. ${ }^{3-5}$ Namun, tidak ada satupun upaya tersebut yang mencegah penurunan tekanan darah, sebaliknya posisi duduk untuk menghambat blokade simpatis yang tinggi telah memberikan efek mengurangi penurunan tekanan darah setelah dilakukan anestesia spinal.

Pada hasil penelitian terhadap pasien yang menjalani seksio sesarea dengan anestesia spinal menggunakan $10 \mathrm{mg}$ bupivakain 0,5\% hiperbarik menunjukkan bahwa efek samping akibat hipotensi seperti mual serta muntah selama operasi berkurang pada kelompok posisi duduk 5 menit setelah anestesia spinal dibanding dengan kelompok yang langsung dibaringkan setelah anestesia spinal (5\% vs 28\%). ${ }^{6}$

Pada penelitian terhadap pasien geriatri yang menjalani operasi urologi menunjukkan bahwa tidak terdapat perbedaan bermakna terhadap perubahan hemodinamik pada posisi duduk selama 2 menit, 5 menit, 10 menit, dan 20 menit setelah anestesi spinal dengan $15 \mathrm{mg}$ bupivakain hiperbarik $0,5 \%$. Hanya saja terjadi perbedaan pada ketinggian blokade sensorik. Ketinggian blokade sensorik tertinggi dalam 30 menit setelah penyuntikan adalah pada posisi duduk selama 2 menit (T5), duduk 5 menit (T7), duduk 10 menit (T10), dan duduk 20 menit (T10). Blokade sensorik mengalami penurunan pada kelompok duduk 10 menit (T12) pada menit ke-50 dan kelompok 20 menit (T12) pada menit ke-50. ${ }^{7}$

Pada penelitian lain terhadap pasien yang menjalani seksio sesarea dengan anestesia spinal dengan menggunakan $15 \mathrm{mg}$ bupivakain 0,5\% hiperbarik menunjukkan bahwa angka kejadian hipotensi lebih kecil pada kelompok posisi duduk 3 menit setelah anestesia spinal dibanding dengan kelompok yang langsung dibaringkan. Demikian juga dengan pemberian efedrin, lebih banyak pada kelompok yang langsung dibaringkan bila dibanding dengan kelompok posisi duduk 3 menit. ${ }^{8}$ Blokade sensorik tertinggi tercapai pada T1 lebih banyak pada kelompok langsung dibaringkan dibanding dengan kelompok posisi duduk 3 menit setelah anestesi spinal (23\% vs $2 \%){ }^{9}{ }^{9}$

Pada penelitian pengaruh posisi duduk dibanding dengan posisi lateral pada 40 pasien yang menjalani seksio sesarea dengan anestesi spinal yang menggunakan $11 \mathrm{mg}$ bupivakain hiperbarik $0,5 \%$ dengan waktu penyuntikan 20 detik dan kemudian kedua kelompok langsung dibaringkan setelah pemberian obat, didapatkan penghambatan blokade sensorik pada menit ke-1 dan ke-5 pada posisi duduk (T6) sebanyak 5 pasien dibanding dengan 8 pasien, menit ke-5 (T6) sebanyak 8 pasien dibanding dengan 14 pasien, dan pada menit ke-45 (T6) sebanyak 15 pasien dibanding 
dengan 18 pasien. $^{10}$

Penelitian ini bertujuan melihat pengaruh duduk 5 menit dibanding dengan langsung dibaringkan setelah pemberian obat anestesia spinal bupivakain 0,5\% hiperbarik $10 \mathrm{mg}$ terhadap tekanan arteri rata-rata (MAP) serta ketinggian blokade sensorik pada pasien yang dilakukan anestesia spinal.

\section{Subjek dan Metode}

Penelitian ini menggunakan uji acak tersamar tunggal (randomized single blind controlled trial). Penelitian dilakukan setelah mendapat persetujuan Komite Etik Penelitian Kesehatan Rumah Sakit Dr. Hasan Sadikin (RSHS) Bandung. Penelitian dilakukan pada bulan Maret-Mei 2015 dengan kriteria inklusi adalah pasien yang menjalani operasi perut bagian bawah dan ekstremitas bawah dengan anestesi spinal di kamar operasi RSHS Bandung, status fisik American Society of Anesthesiologist (ASA) I-II. Kriteria eksklusi adalah pasien dengan tinggi badan $<175 \mathrm{~cm}$ atau $>155 \mathrm{~cm}$ serta pasien dalam terapi obat hipertensi. Kriteria pengeluaran adalah blokade spinal gagal.

Penentuan jumlah sampel menggunakan rumus untuk menguji perbedaan rata-rata pada dua perlakuan dengan power test $80 \%$
$\left(\mathrm{Z}_{\beta}=0,84\right)$. Didapatkan jumlah sampel minimal untuk kelompok masing-masing adalah 16 orang ditambah dengan 10\% kemungkinan pengeluaran sampel sehingga jumlah sampel tiap kelompok adalah 18 orang maka total sampel adalah 36 orang.

Penelitian ini dibagi menjadi dua kelompok, kelompok 1 (18 pasien) adalah kelompok posisi duduk 5 menit setelah anestesi spinal kemudian dibaringkan dan kelompok 2 (18 pasien) kelompok posisi langsung dibaringkan setelah anestesi spinal. Kelompok masingmasing diberikan obat anestesi lokal $10 \mathrm{mg}$ bupivakain $0,5 \%$ hiperbarik dengan kecepatan penyuntikan $1 \mathrm{~mL} / 5$ detik.

Efektivitas blokade sensorik dinilai dengan uji pin-prick yang dimulai 5 menit setelah penyuntikan dan diukur ketinggian blokade setiap 2,5 menit sampai menit ke-30. Variabel tekanan arteri rata-rata diukur saat pasien datang sebagai data awal dan setiap 2,5 menit sampai menit ke-30 setelah penyuntikan. Pada penelitian ini, efedrin diberikan apabila subjek penelitian mengalami hipotensi atau penurunan tekanan arteri rata-rata lebih dari $20 \%$ tekanan arteri rata-rata awal.

Data dianalisis dengan menggunakan Uji Shapiro Wilk, Kolmogorov Smirnov, dan MannWhitney dengan tingkat kepercayaan 95\% dan

Tabel 1 Karakteristik Umum Pasien Kedua Kelompok

\begin{tabular}{|c|c|c|c|}
\hline \multirow[b]{2}{*}{ Variabel } & \multicolumn{2}{|c|}{ Kelompok } & \multirow[b]{2}{*}{ Nilai p } \\
\hline & $\begin{array}{c}1 \\
(n=18)\end{array}$ & $\begin{array}{c}2 \\
(n=18)\end{array}$ & \\
\hline Usia (tahun) & & & 0,918 \\
\hline Mean \pm SD & $51,44 \pm 18,07$ & $50,89 \pm 13,67$ & \\
\hline Median & 57,5 & 56 & \\
\hline Range & $20-80$ & $26-72$ & \\
\hline Tinggi badan $(\mathrm{cm})$ & & & 0,293 \\
\hline Mean \pm SD & $162,27 \pm 6,46$ & $164,33 \pm 7,97$ & \\
\hline Median & 165 & 167 & \\
\hline Range & $150-172$ & $152-176$ & \\
\hline $\begin{array}{l}\text { Tekanan arteri rata-rata } \\
(\mathrm{mmHg})\end{array}$ & & & 0,571 \\
\hline Mean \pm SD & $93,77 \pm 7,21$ & $98,94 \pm 2,99$ & \\
\hline Median & 95,5 & 99 & \\
\hline Range & $74-103$ & $95-104$ & \\
\hline
\end{tabular}

Keterangan: nilai p dengan Uji Shapiro Wilk. Tanda \# menunjukkan nilai $\mathrm{p}<0,05$ artinya signifkan atau bermakna secara statistik 
Tabel 2 Perbandingan Penurunan Tekanan Arteri Rata-rata antara Kedua Kelompok

\begin{tabular}{|c|c|c|c|c|c|c|c|c|}
\hline \multirow{3}{*}{$\begin{array}{l}\text { Waktu } \\
\text { (menit) }\end{array}$} & \multirow{3}{*}{ Delta } & \multicolumn{6}{|c|}{ Kelompok } & \multirow{3}{*}{ Nilai p } \\
\hline & & \multicolumn{3}{|c|}{$1(n=18)$} & \multicolumn{3}{|c|}{$2(n=18)$} & \\
\hline & & $\begin{array}{c}\text { Rata-rata } \\
\text { (mmHg) }\end{array}$ & $\%$ & SD & $\begin{array}{c}\text { Rata-rata } \\
\text { (mmHg) }\end{array}$ & $\%$ & SD & \\
\hline $0-2,5$ & $\mathrm{t} 1-\mathrm{t} 0$ & $-0,88$ & 0,80 & 2,80 & $-3,05$ & 3,10 & 3,11 & ${ }^{\#} 0,020^{* *}$ \\
\hline $2,5-5$ & $\mathrm{t} 2-\mathrm{t} 1$ & $-1,33$ & 1,30 & 2,35 & $-2,72$ & 2,80 & 3,42 & $0,279^{* *}$ \\
\hline $5-7,5$ & $\mathrm{t} 3-\mathrm{t} 2$ & $-1,27$ & 1,40 & 3,26 & $-1,44$ & 1,60 & 2,83 & $0,406^{* *}$ \\
\hline $7,5-10$ & $\mathrm{t} 4-\mathrm{t} 3$ & $-0,77$ & 0,80 & 2,86 & $-2,38$ & 2,70 & 2,81 & ${ }^{\#} 0,020^{* *}$ \\
\hline $10-12,5$ & $\mathrm{t} 5-\mathrm{t} 4$ & $-1,55$ & 1,70 & 2,22 & $-1,27$ & 1,20 & 4,25 & $0,650^{* *}$ \\
\hline $12,5-15$ & $\mathrm{t} 6-\mathrm{t} 5$ & 0,22 & 0,20 & 2,34 & $-1,00$ & 1,00 & 3,06 & $0,091^{* *}$ \\
\hline $15-17,5$ & $\mathrm{t} 7-\mathrm{t} 6$ & $-0,72$ & 0,70 & 2,39 & $-2,22$ & 2,60 & 2,94 & $0,265^{* *}$ \\
\hline $17,5-20$ & t8-t7 & $-0,05$ & 0,03 & 3,28 & $-1,16$ & 1,30 & 2,93 & $0,143^{* *}$ \\
\hline $20-22,5$ & $\mathrm{t} 9-\mathrm{t} 8$ & 0,22 & 0,37 & 3,00 & $-2,27$ & 2,80 & 2,02 & ${ }^{\#} 0,003^{* *}$ \\
\hline $22,5-25$ & $\mathrm{t} 10-\mathrm{t} 9$ & $-2,05$ & 2,34 & 6,14 & 0,94 & 1,93 & 11,32 & $0,673^{* *}$ \\
\hline $25-30$ & $\begin{array}{c}\mathrm{t} 11- \\
\mathrm{t} 10\end{array}$ & $-0,66$ & 0,56 & 3,21 & $-2,27$ & 2,41 & 6,31 & $0,963^{* *}$ \\
\hline Rata-rata & & $-0,80$ & 0,82 & & $-1,73$ & 1,66 & & \\
\hline
\end{tabular}

Keterangan: tanda * menunjukkan uji-t tidak berpasangan dan tanda ** menunjukkan Uji Mann-Whitney. Tanda " menunjukkan nilai $\mathrm{p}<0,05$ artinya signifkan atau bermakna secara statistik

dianggap bermakna bila $\mathrm{p}<0,05$ dan sangat bermakna bila $\mathrm{p}<0,001$. Data disajikan dalam rata-rata (mean) dan dianalisis menggunakan program statistical product and service solution (SPSS) 21 for windows.

\section{Hasil}

Hasil uji data karakteristik umum terhadap subjek penelitian menunjukkan bahwa tidak terdapat perbedaan yang bermakna pada usia, tinggi badan, dan tekanan arteri rata-rata awal pada kedua kelompok ( $p>0,05$; Tabel 1).
Penurunan tekanan arteri rata-rata lebih besar pada kelompok 2 dibanding dengan kelompok 1 dengan perbedaan yang bermakna berdasarkan Uji Mann Whitney $(\mathrm{p}<0,05$; Tabel 2).

Tinggi blokade sensorik pada kelompok 1 terbanyak pada T10 (14 dari 18), sedangkan pada kelompok 2 terbanyak pada T6 (8 dari 18; Tabel 3).

\section{Pembahasan}

Anestesia spinal merupakan teknik anestesia

Tabel 3 Perbandingan Tinggi Blokade Sensorik antara Kedua Kelompok

\begin{tabular}{|c|c|c|c|}
\hline \multirow{2}{*}{$\begin{array}{c}\text { Variabel } \\
\text { Tinggi Blokade Sensorik }\end{array}$} & \multicolumn{2}{|c|}{ Kelompok } & \multirow[b]{2}{*}{ Nilai $\mathbf{p}^{* *}$} \\
\hline & $\begin{array}{c}1 \\
(n=18)\end{array}$ & $\begin{array}{c}2 \\
(n=18)\end{array}$ & \\
\hline T5 & 0 & 1 & 0,001 \\
\hline T6 & 1 & 8 & \\
\hline $\mathrm{T} 7$ & 0 & 2 & \\
\hline T8 & 2 & 6 & \\
\hline T9 & 1 & 0 & \\
\hline $\mathrm{T} 10$ & 14 & 0 & \\
\hline
\end{tabular}

Keterangan: nilai p dengan Uji Kolmogorov Smirnov menunjukkan nilai $p<0,05$ artinya bermakna secara statistik 
pilihan yang digunakan pada operasi perut bagian bawah dan ekstremitas bawah karena mempunyai keuntungan, di antaranya tingkat analgesia yang kuat, risiko aspirasi lebih kecil, relaksasi otot cukup, serta pemulihan fungsi saluran pencernaan lebih cepat., ${ }^{2,5}$ Berbagai inovasi terhadap teknik dan obat-obatan dikembangkan untuk mendapatkan hasil yang lebih baik dan mengurangi efek samping anestesia spinal, yaitu penurunan tekanan arteri rata-rata sampai terjadinya hipotensi. Salah satunya dengan teknik posisi duduk setelah dilakukan anestesia spinal.

Bupivakain 0,5\% hiperbarik merupakan obat anestesia lokal yang sering dipergunakan pada anestesia spinalyang mempunyai densitas tiga standar deviasi (SD) di bawah densitas cairan serebrospinal. Mekanisme penyebaran bupivakain hiperbarik dipengaruhi oleh gaya gravitasi atau posisi tubuh saat duduk dan juga oleh lekukan kolumna vertebralis. Lekukan kolumna vertebralis berpengaruh terhadap penyebaran obat anestesia lokal hiperbarik di dalam ruang subaraknoid, pada posisi tubuh terlentang titik tertinggi berada di lumbal tiga dan titik terendah berada di torakal lima.

Berdasarkan pada data karakteristik umum subjek penelitian menunjukkan bahwa tidak terdapat perbedaan bermakna antara kedua kelompok dalam hal usia, tinggi badan, dan tekanan arteri rata-rata. Hal ini menunjukkan bahwa subjek dalam penelitian homogen dan layak untuk dibandingkan ( $p>0,05$; Tabel 1).

Penurunan tekanan arteri rata-rata lebih besar pada kelompok 2 bila dibanding dengan kelompok 1 , yaitu $1,73 \mathrm{mmHg}(1,66 \%)$ vs 0,80 mmHg $(0,82 \%)$ secara statistik bermakna $(p<0,05 ;$ Tabel 2). Keadaan ini disebabkan pada posisi duduk 5 menit setelah anestesia spinal dengan $10 \mathrm{mg}$ bupivakain 0,5\% hiperbarik terjadi penghambatan penyebaran obat ke titik rendah pada saat posisi tubuh dibaringkan. Pada posisi duduk selama 5 menit, bupivakain hiperbarik lebih banyak menetap di bawah lokasi penusukan sehingga saat posisi tubuh dibaringkan terjadi penghambatan regresi ke titik rendah yang menyebabkan blokade simpatis rendah, penurunan tahanan vaskular lebih kecil maka penurunan tekanan arteri rata-rata lebih kecil. Pada posisi langsung dibaringkan blokade simpatis lebih tinggi yang menyebabkan penurunan tahanan vaskular sehingga penurunan tekanan arteri ratarata terjadi lebih besar pada posisi langsung dibaringkan.

Secara klinis perbedaan penurunan tekanan arteri rata-rata pada kedua kelompok tidak bermakna, tidak terjadi penurunan tekanan arteri rata-rata lebih dari $20 \%$ tekanan arteri rata-rata awal. Tidak ditemukan hipotensi pada kedua kelompok, hal ini terjadi karena pada kedua subjek penelitian telah diberikan cairan kristaloid $10 \mathrm{~mL} / \mathrm{kgBB}$ sebelum dilakukan anestesi spinal. Pemberian obat anestesi lokal disuntikan secara lambat dengan $1 \mathrm{~mL}$ selama 5 detik sehingga penyebaran obat berdifusi lambat dan tingkat analgesia yang dicapai rendah.

Ketinggian blokade sensorik rata-rata pada kelompok 1 terbanyak pada T10 (14 dari 18), sedangkan pada kelompok 2 terbanyak pada T6 (8 dari 18) dan di T8 sebanyak 6 dari 18. Berdasarkan hasil uji statistik menggunakan uji Kolmogorov Smirnov menunjukkan tinggi blokade sensorik pada kedua perlakuan berbeda bermakna secara statistika $(\mathrm{p}<0,05$; Tabel 3). Hal ini disebabkan karena setelah 30 menit penyuntikan anestesi spinal, bupivakain hiperbarik tersebut terfiksasi sehingga pada posisi duduk 5 menit penyebaran obat lebih lambat ke titik terendah maka blokade sesorik yang tercapai akan lebih rendah.

Efedrin diberikan apabila subjek penelitian mengalami hipotensi atau penurunan tekanan arteri rata-rata lebih dari 20\% tekanan arteri rata-rata awal. Selama 30 menit setelah dilakukan anestesia spinal, penurunan tekanan arteri rata-rata lebih kecil pada kelompok 1 dibanding dengan kelompok 2 .

\section{Simpulan}

Posisi duduk selama 5 menit setelah tindakan anestesia spinal dengan menggunakan $10 \mathrm{mg}$ bupivakain $0,5 \%$ hiperbarik menghasilkan penurunan tekanan arteri rata-rata yang lebih kecil dibanding dengan posisi langsung dibaringkan. Ketinggian blokade sensorik juga 
lebih rendah pada kelompok posisi duduk selama 5 menit bila dibanding dengan posisi langsung dibaringkan.

\section{Daftar Pustaka}

1. Kettner SC, Willschke H, Morhofer P. Does regional anesthesia realy improve outcome. Br J Anesth. 2011;107(51):1905.

2. Hocking G, Wildsmith JAW. Intrathecal drug spread. Br J Anesth. 2005;94:249-52.

3. Morgan E, Mikhail MS, Murray MJ. Clinical anesthesiology. Edisi ke-4. New York: McGraw Hill; 2006.

4. Duke J. Spinal anesthesia. Anesthesia secrets. Edisi ke-3. Philadelphia: MosbyElsevier; 2006.

5. Bernards CM. Epidural and spinal anesthesia. Dalam: Barash PG, Cullen $\mathrm{BF}$, Stoelting RK, penyunting. Clinical anesthesia. Edisi ke-5. Philadelphia: Lipincott William and Wilkins Co; 2006. hlm. 691-717.

6. Essam E, Abd EL, Abdllah M, Adnan A,
Mansouri AL, Jamal A, dkk. Effects of sitting up for five minutes versus immediately lying down after spinal anesthesia for cesarean delivery on fluid and ephedrine requirement. Can J Anesth. 2011;58:10839.

7. Shazad KH, Afshan G. Induction potition for spinal anaesthesia: sitting versus lateral position. Pakistan J Med Anesth. 2013;63:54-9.

8. Akhtar MN, Tariq S, Abbas. Haemodynamic changes in patient undergoing spinal anaesthesia. Eur J Anesth. 2012;22:74750 .

9. Ngan Kee WD. Prevention of maternal hypotension after regional anaesthesia for caesarean section. Curr Opin Anaesthesiol. 2010;23(3):304-9.

10. Chevuri SB, Subba JV, Chandergutti V, Hussain MH, Khan BA. A comperative of effects of sitting and lateral position on quality of block during induction of spinal anaesthesia in patients undergoing cesarean section. Denmark J Med Anesth. 2015;3:93-5. 